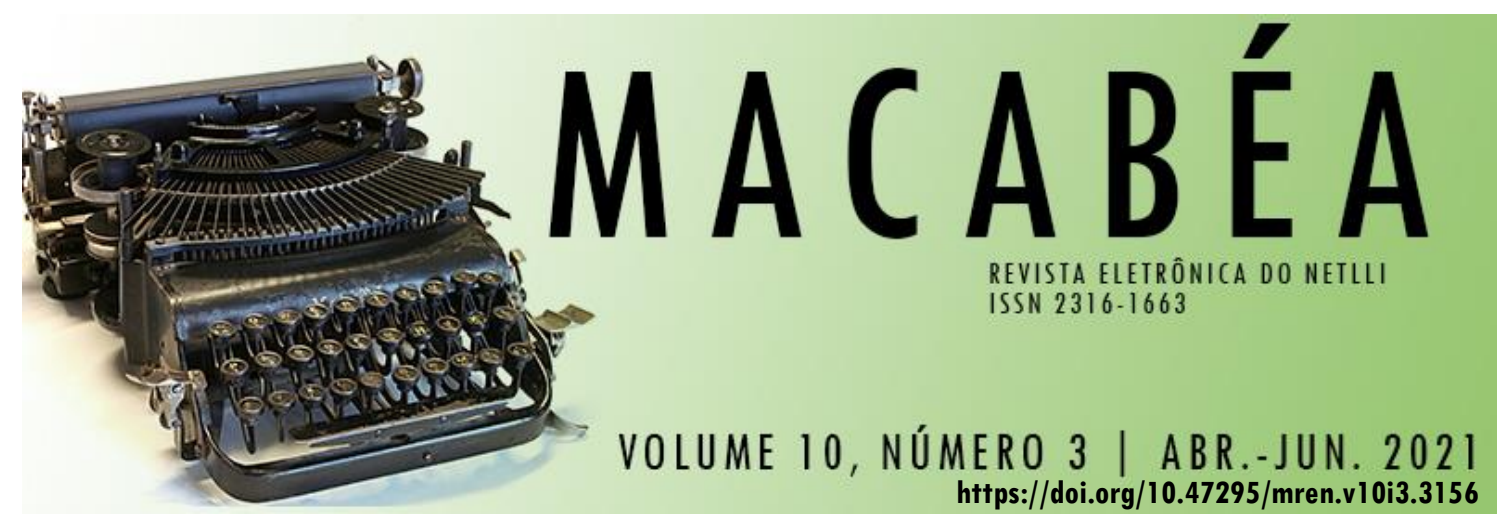

\title{
A INSISTÊNCIA DO SIGNIFICANTE EM SATOLEP, DE VITOR RAMIL
}

\section{THE INSISTENCE OF THE SIGNIFIER IN SATOLEP, BY VITOR RAMIL}

AROLDO GARCIA DOS ANJOS

\author{
RESUMO | INDEXAÇÃO | TEXTO | REFERÊNCIAS | CITAR ESTE ARTIGO | 0 AUTOR \\ RECEBIDO EM 31/01/2021 • APROVADO EM 06/03/2021
}

\begin{abstract}
The present work is linked to investigations of a historical anthropology of language and presents an interpretation of the work Satolep, by Vitor Ramil, in order to think the time in its enunciative dimension. To this end, a theoretical approach between Walter Benjamin and Émile Benveniste, as proposed by Giorgio Agamben, is taken as basis. Here, this approach is deepened from the point of view of time. This discussion aims to observe the constitutive time in Satolep, which is the foundation of a subjectivity in the process of actualization and singularization of human experience. Finally, it is observed how the portraitist protagonist Selbor inscribes himself in what he describes in his displacements.
\end{abstract}

\section{Resumo}

0 presente trabalho filia-se às investigações acerca de uma antropologia histórica da linguagem e apresenta uma leitura sobre a obra Satolep, de Vitor Ramil, de modo a realizar uma reflexão sobre o tempo que leve em conta a sua dimensão enunciativa. Para tanto, parte de uma aproximação teórica entre Walter Benjamin e Émile Benveniste, proposta por Giorgio Agamben. Tal aproximação é aprofundada, aqui, pelo viés do tempo. Objetiva-se, com essa discussão, observar, em Satolep, o tempo constituidor, fundante de uma subjetividade no processo de atualização e de singularização da experiência humana. Observa-se como, em última instância, o protagonista retratista Selbor se inscreve no que descreve em seus deslocamentos. 


\section{Entradas para indexação}

KEYWORDS: Language. Subjectivity. Time. Signifier. Satolep.

PALAVRAS-CHAVE: Linguagem. Subjetividade. Tempo. Significante. Satolep.

\section{Texto integral}

\section{CONSIDERAÇÕES INICIAIS}

O presente trabalho visa a apresentar uma leitura ${ }^{1}$ sobre a obra Satolep, de Vitor Ramil, de modo a realizar uma reflexão sobre o tempo que leve em conta a sua dimensão enunciativa. 0 trabalho situa-se em um entre-lugar teórico, uma vez que parte de discussões de linguagem caras tanto à literatura quanto à linguística. Para tanto, parte de uma aproximação teórica entre Walter Benjamin e Émile Benveniste, proposta por Giorgio Agamben em Infância e história: ensaio sobre a destruição da experiência, de 1979. No ensaio em questão, Agamben discute o lugar ao qual foi relegada a experiência humana na tradição ocidental, assim como a concepção de linguagem que lhe subjaz.

Com Benjamin, Benveniste e Saussure, Agamben (2008, p. 58) conclui que a experiência já é sempre "palavra", o que implica a consideração de que não há sujeito a priori, uma vez que este é constituído na linguagem e pela linguagem. Segundo a leitura de Agamben, o sujeito torna-se sujeito ao entrar na linguagem. Para Benveniste, não há humano fora da linguagem, pois ela está na natureza do homem, que não a criou. É na enunciação, na e pela linguagem, que o homem entra na história. A radical transformação da língua, ao constitui-la como discurso, é uma condição do homem. 0 humano é história, é essa passagem da língua ao discurso, é devir (AGAMBEN, 2008, p. 67-68). Sua concepção de linguagem volta-se, com isso, ao que é da ordem da singularidade.

Tal aproximação é aprofundada, no trabalho em questão, pelo viés do tempo. Objetiva-se, com essa discussão, observar, em Satolep, o tempo constituidor, fundante de uma subjetividade no processo de atualização e de singularização da experiência humana. A análise é feita, pois, a partir de discussões levantadas por Giorgio Agamben, Walter Benjamin e Émile Benveniste. Gérard Dessons e Henri Meschonnic também são convocados à discussão, enquanto teóricos e leitores da obra de Benveniste.

Com base na consideração da atualização ${ }^{2}$, observamos que, desde seu título e sua apresentação visual, Satolep parece instigar a pensar o espaço, mas que, porém, isso lentamente se transmuta em um retorno no tempo, que, tomado em sua

\footnotetext{
${ }^{1}$ A presente reflexão é um excerto da dissertação intitulada Lavrar a névoa: o tempo em Satolep, de Vitor Ramil, defendida em julho de 2020 junto ao Programa de Pós-Graduação em Letras da UFPel.

2 A respeito de "atualização", encontram-se discussões específicas em Pachalski \& Anjos (2019) e em Neumann \& Anjos (2020). Em minha dissertação, aprofundo a discussão sobretudo na subseção "O semiótico, o semântico e a atualização", p. 73-80.
} 
condição constitutiva, é também tema da narrativa, em sua forma e em seus sentidos. Observa-se como, em última instância, Selbor (o protagonista retratista) se inscreve no que descreve. Percebe-se assim, com Satolep, que o processo de subjetivação é íntimo ao de sintagmatização e de semantização. Na obra, as constantes comparações entre a memória, a cidade e a água reforçam sua ligação à temporalidade, impondo-se pela insistência dos significantes. Desse modo, Satolep versa, simultaneamente, tanto sobre a voracidade do tempo quanto sobre sua constante recomposição, pois, como nos lembra Benveniste, em toda tomada da palavra, o mundo recomeça. 0 tempo em Satolep insiste em se dizer.

\section{A INSISTÊNCIA DO SIGNIFICANTE}

Contrapondo-se ao primado do signo, no ensaio Le signe et le poème, Meschonnic observa uma significância em constante processo de ser feita e desfeita. Essa significância é uma "significação produzida pelo significante ${ }^{3}$ " (MESCHONNIC, 1975, p. 512), não derivada de uma oposição entre significante e significado. A poesia e a escritura seriam modalidades dessa significância. 0 autor afirma que "não é o significante linguístico que é um sujeito", mas sim o "sujeito da escritura que é um complexo de significantes, linguísticos e não linguísticos" " (MESCHONNIC, 1975, p. 515). 0 antropológico, realça assim Meschonnic, está inscrito na prática do discurso, "Como o sujeito que não escreve, pelo menos da maneira reconhecida na escritura5" (MESCHONNIC, 1975, p. 515). Visto dessa forma, o processo de subjetivação é íntimo ao de sintagmatização e de semantização, descritos por Benveniste.

Notemos que, tomado em sua condição constitutiva, o tempo, em Satolep, é também tema da narrativa, em sua forma e em seus sentidos. Cabe aqui observar, por sua recorrência, como alguns significantes surgem, ressurgem e adquirem valor na globalidade do texto; como, em última instância, Selbor se inscreve no que descreve.

A recorrência de termos atinentes ao tempo, assim como as reflexões tecidas sobre seu estatuto, evidencia a sua centralidade na obra em questão. Desde a epígrafe de Santo Agostinho, já observamos essa insistência: "Dispersei-me no tempo cuja ordem ignoro" (RAMIL, 2008, p. 5). Que pistas nos dá a epígrafe extraída do Livro XI das Confissões? É sobre a natureza da criação do tempo que versará Satolep? Sobre a relação do tempo com a eternidade? Reflexão sobre corpo e alma? Ponderações introspectivas sobre as próprias memórias e sobre si mesmo? A implicação do narrador naquilo que narra?

Em diversas passagens, o narrador confessa seu estado de confusão, associando sua instabilidade a uma espécie de vertigem da temporalidade, um tempo-espaço pouco sólido: "Eu deixava sob suspeita o presente e a realidade,

\footnotetext{
${ }^{3}$ Tradução minha. No original: "signification produite par le signifiant".

${ }^{4}$ Tradução minha. No original: “Ce n'est pas le signifiant linguistique qui est un sujet (...). C'est le sujet de l'écriture qui est un complexe de signifiants, linguistiques et non linguistiques".

5 Tradução minha. No original: "Comme le sujet qui n'écrit pas, du moins de la façon reconnue dans l'écriture".
} 
tempo e espaço" (RAMIL, 2008, p. 145). Começa a diluir-se o vai-e-vem entre os caminhos de pedra - do dia, da cidade racionalizada - e os do sonho - associado à noite, à literatura, aos artistas, aos loucos. Os elementos objetivos vão perdendo sua força, convertendo-se em fantasmagorias, como "um grito no passado" (RAMIL, 2008, p. 210). Essas vertigens precipitam Selbor aos caminhos de sonho, da linguagem onírica.

Na cena do sarau de fumaça (RAMIL, 2008, p. 182-198), quando Selbor, após fumar um Marca-Diabo, conversa com seus amigos artistas, que se lhe aparecessem vindos das tragadas que ele dá no cigarro, o principal tema se torna novamente o tempo. Insistentemente Heráclito é citado: "primeiro, o tempo é criança brincando, jogando; depois, que o fogo é o tempo físico, a inquietude absoluta, a absoluta dissolução do que persiste, o desaparecer dos outros e de si mesmo, a impermanência" (RAMIL, 2008, p. 184).

Jorge Luis Borges também é relembrado ao ter um verso de El reloj de arena recitado pelo Compositor: "el curso irrevocable del agua que prosigue su camino" (RAMIL, 2008, p. 192). Nos versos, água e tempo são diretamente associados. No poema de Borges, há, não por acaso, referência ao filósofo: "el agua de aquel río en que Heráclito vio nuestra locura".

As referências à umidade vão adquirindo o valor dos caminhos do sonho, da ordem do inconsciente: "eu dera uma volta em mim mesmo para terminar isolado diante de coisa nenhuma sobre uma cidade submersa" (RAMIL, 2008, p. 178). Mesmo após o retorno de Selbor a Satolep, os rios continuam a ser evocados: "Naquele grupo, éramos um só e muitos rios de Heráclito a fluir" (RAMIL, 2008, p. 221). Da mesma forma, as comparações entre a memória, a cidade e a água aumentam, reforçando sua ligação à temporalidade. 0 tempo em Satolep insiste em se dizer.

\section{A CONSTRUÇÃO DO TEMPO}

Como defendemos, Satolep propõe o tempo, mas surge como uma miragem espacial. Não há, pois, uma cronologia marcada em evidência em Satolep. Não há datas explícitas. A passagem do tempo é indiciada, aqui ou ali, por esparsas referências a estações do ano, que deixam implícita a passagem de um ano, cumprindo-se um ciclo. É necessário tentar entender como se dá a construção do tempo.

Como vimos, no entanto, há desdobramentos narrativos que determinam a questão do tempo. 0 relato do personagem narrante parte de dentro de uma sala em uma instituição de saúde, originando-se, dentro dele, um personagem narrado que se enuncia noutros tempos e espaços. As intromissões do narrador da história primeira, dirigindo-se ao leitor, evidenciam esse encaixe, subordinando a segunda narrativa à primeira: "Os senhores se lembram de quando eu vivia perto do sol?" (RAMIL, 2008, p. 34) e "narrativa cujo desfecho melancólico os senhores já conhecem" (RAMIL, 2008, p. 44).

Dentro da segunda narrativa, há ainda a inserção das fotos e textos da pasta preta, que funcionam como outras vozes narrativas dentro da história, 
influenciando-a, criando um jogo de espelhos. Essa inserção gradual do conteúdo da pasta na narrativa provoca, além do suspense, uma outra problematização do tempo. Na pasta, Selbor depara-se com retratos que ele ainda baterá e com textos escritos em um passado desconhecido. Esses elementos antecipam a ação do personagem, forçando-o à obsessiva busca em decifrar o enigma da pasta. Concomitantemente, essas narrativas parecem encaminhar o destino da personagem rumo à tragédia, com seus avisos sobre a voracidade do tempo e a presença da loucura.

Buscamos apoio, aqui, na leitura que Dessons faz de Benveniste, para observarmos a construção do tempo em Satolep. Em Émile Benveniste e a arte de pensar, Dessons, ao dissertar sobre a consideração da enunciação como uma problemática global, afirma que um pressuposto em Benveniste é o da natureza enunciativa da fala, indissociável da subjetividade: "se a enunciação designa a atividade de um sujeito em sua linguagem, então toda fala é por natureza enunciativa" (DESSONS; NEUMANN; OLIVEIRA, 2020, p. 377).

Dessons afirma que há, no entanto, uma diferença entre o discurso ordinário, calcado nos "marcadores de enunciação conforme uma tipologia compartilhada por todos os locutores de um grupo linguístico (dêiticos, modalizadores, etc.)" (DESSONS; NEUMANN; OLIVEIRA, 2020, p. 377), e outros tipos de discurso - como o poema ou o delírio - que operam de modo diferente ao criar os seus próprios marcadores subjetivos. Trata-se, aqui, de uma "aventura da linguagem (e devir de um sujeito)" (DESSONS; NEUMANN; OLIVEIRA, 2020, p. 377), na qual já não mais nos encontramos em "terreno familiar", mas encaramos o desconhecido - as terrae incognitae, pelas palavras de Benveniste (DESSONS; NEUMANN; OLIVEIRA, 2020, p. 377).

Dessons compreende que na literatura, cujo conjunto de discurso "se torna um marcador potencial de subjetividade" (DESSONS; NEUMANN; OLIVEIRA, 2020, p. 377), todos os marcadores estão embaralhados (sont brouillés), confusos. Já não há mais limites claros entre as categorias (índices de pessoa, marcadores espaciotemporais, ...), visto que elas se interpenetram, reestabelecendo-se dentro de uma globalidade própria, a do poema.

Uma pergunta se impõe: em uma análise a partir dessa reflexão sobre linguagem, como relacionar o aqui e agora da enunciação, de Benveniste, com o aqui e outrora do Jetztzeit ${ }^{6}$, de Benjamin? Trata-se de um lembrar reconstrutor, ativo, sempre a partir do presente? Uma subjetividade que se cria a partir das recordações e dos desdobramentos? Simultaneidades?

Como observado em Benjamin (2011) e em Benveniste (2006), a expressão da temporalidade é subjetiva, visto a indissociabilidade entre tempo e pessoa. É o ato de apropriação das formas pronominais que permite a passagem de locutor a sujeito: "eu, criança, mais rápido que o tempo, também ainda não passara" (RAMIL, 2008, p. 11), "eu, pretensiosa abstração" (RAMIL, 2008, p. 15), "suspeita de ser eu mesmo" (RAMIL, 2008, p. 180). Como vimos, "a marca temporal do presente só pode ser interior ao discurso (BENVENISTE, 2005, p. 289). Temos, com Benveniste, uma enunciação que ressignifica outras em um aqui e agora. $\mathrm{Na}$ coincidência de acontecimentos e instância de fala, funda-se o presente, onde há sujeito e história.

\footnotetext{
${ }^{6}$ Em minha dissertação, na subseção “Benjamin: linguagem e tempo, um presente cheio de passado", p. 40-51, apresento o conceito benjaminiano de Jetztzeit, tempo-agora.
} 
Instaura-se, aí, a temporalidade, organizando-se ao redor de "eu" as referências espaciais e temporais:

\begin{abstract}
Mas agora, tantos anos e lugares depois, em sons de charretes, palavras, perfumes de damas-da-noite, alguns casarões, algumas noites, coisas indistintas, lá estava ela outra vez, como algo de que eu necessitasse. Satolep ainda não passara (RAMIL, 2008, p. 11)
\end{abstract}

Em especial, aproximamos Benveniste e Benjamin pela forma como concebem o presente. Em Benjamin, a enunciação, ao ser produzida, já possui outras em seu bojo, em negociação com o presente, como anuncia em seu projeto das Passagens: "Não é que o passado lança luz sobre o presente ou que o presente lança sua luz sobre o passado; mas a imagem é aquilo em que o ocorrido encontra o agora num lampejo, formando uma constelação" (BENJAMIN, 2009, p. 504).

Ao mesmo tempo em que é a partir desse presente que se constrói passado e futuro, também esse presente dialoga com o passado, com outros discursos que, tendo sua enunciação acabada, já estão no passado. É justamente nesse ponto de ressignificação que podemos aproximar Benveniste e Benjamin, afinal, para ambos autores, é no presente que se dá a atualização. Pensando em termos saussurianos, caros a Benveniste, o que constitui valor não é só o que está em presença, mas também as relações em ausência. Atualizar seria, assim, presentificar em uma sincronia, in præsentia, o que constitui valor na diacronia, in absentia. Os acontecimentos passados são, assim, evocados pela memória (BENVENISTE, 2006, p. 75), atualizados na instância de fala que se refere a si mesma, ressignificando-se constantemente. 0 tempo é voz, é singularidade. Onde há voz, há sujeito e história.

\title{
4. NOVOS MATIZES: A RESSIGNIFICAÇÃO
}

Observamos na subseção anterior que a construção do tempo se dá marcada por um fator subjetivo primordial a partir do qual ocorre, inevitavelmente, a ressignificação: a apropriação da língua. Por ressignificação aqui, não pensamos apenas em acontecimentos atualizados na instância de discurso que refere a si mesma, mas também, posto que indissociável, nas palavras semantizadas nesse discurso, em seus possíveis novos matizes ${ }^{7}$. Segundo Neumann, a partir de Meschonnic, pensar as problemáticas da voz e da linguagem enquanto antropológicas e, portanto, indissociáveis do sujeito, permite-nos "afirmar que a voz é a organização do sujeito no discurso, o sentido é uma atividade do sujeito" (2017, p. 668). Do mesmo modo, como bem aponta Dessons (2020, p. 337), na linguagem

\footnotetext{
${ }^{7}$ Para usar uma imagem de Über die Farbe der Wörter und Sprachen (Sobre a cor das palavras e das línguas), de Jürgen Trabant, que observa que as línguas passaram a receber qualidades visuais - e cores - quando foram percebidas como cognitivas, semânticas - como o "órgão formador do pensamento" (HUMBOLDT apud TRABANT, 2016, p. 42). Tradução minha, no original: "das bildende Organ des Gedanken".
} 
literária, as categorias de pessoa, tempo e espaço se confundem profundamente. Interessa-nos observar o que pode resultar, na obra em questão, desse entrelaçamento, perguntando-nos o que se ressignifica em Satolep.

Ao retornar de uma temporada no campo e, no caminho de volta, parar para visitar uma casa aparentemente abandonada, na área de várzea próxima à cidade: Selbor é interpelado por recordações, que se misturam à situação: "0 meu tempo todo em toda parte. Eu tinha dado uma volta em mim mesmo. [...] 0 trem me trazia da remota queda em uma escada; a casa sobre pilotis me mantinha no alto de outra escada" (p. 161). Selbor fica ilhado em função de uma forte e incessante chuva:

Imagens do que eu vivera fluíam sua realidade no que eu vivia feito água que me escorresse entre os dedos sem molhar. A essa presença ausente, o tempo opunha com ironia infinita a evidência inelutável de uma chuva que logo desceria sobre minha carne triste (RAMIL, 2008, p. 162).

Como a seguir os conselhos do irmão mais velho, que também são entoados pelo Rapaz, Selbor parece tentar aprender a ver o que no seu presente lhe permite entender melhor seus fantasmas familiares e, com isso, ressignificar seu impasse com o mundo. Se pensarmos com Benjamin, esse resgate reconstrutivo só pode se dar por uma brusca interrupção da linearidade: "parar nas coisas para perceber devidamente o presente" (RAMIL, 2008, p. 157). Que ruínas mais restariam a revolver, pergunta-se Selbor: "Em minha vida parecia haver subtrações cujas zonas de sombra me alcançavam com a realidade do temporal” (RAMIL, 2008, p. 166).

Em diversos objetos Selbor vê reflexos de sua infância, como na lata tisnada junto a um vidro de álcool. Adentrar esse espaço funciona, para o fotógrafo, como uma estranha fusão de tempos e espaços: "fora atraído menos pela plasticidade do lugar que pela síntese de outros lugares que ele representava" (RAMIL, 2008, p. 168). Associados ao tempo, ecoam, nessa cena, os comentários do personagem sobre se sentir entrando em uma espiral. Termos como "volta", "círculo", "ciclo" são usados com frequência, remetendo à ideia de tempos que emergem dentro do tempo, ou vozes, pela leitura de Benjamin: "Não existem, nas vozes que escutamos, ecos das vozes que emudeceram?” (1989, p. 223). Ou através de Benveniste: "evocados pela memória" (2006, p. 75).

Ao ouvir o ressoar de um sino fora da casa, Selbor corre em direção à porta de saída e cai escada abaixo. 0 narrador acrescenta ao relato: "O interessante é que meus pensamentos se precipitaram comigo quando deveriam ter ficado nas nuvens, que era onde eu tinha a cabeça" (RAMIL, 2008, p. 169). Em meio à fúria da várzea transtornada, ocorrem a Selbor insistentes pensamentos sobre essa queda: "Ela não estava lá. Minha mãe, senhores, ela não estava lá” (RAMIL, 2008, p. 170). 0 sino repercute na memória de Selbor como os gritos da mãe trancada em seu quarto. Ocorre, aqui, algo como a fusão de espaços e tempos que, ao associar essa queda a uma outra na casa da infância, traz consigo a tristeza da mãe pela partida do filho mais velho, bem como o sofrimento do caçula por querer se sentir responsável por aquilo. 
Como em uma espécie de delírio, ainda que encoberto pela desfaçatez do narrador, Selbor se pergunta se está começando a aprender a ver aquela presença encoberta que se alardeava, aquele pingo de luz sob o sino que "iluminara uma zona de sombra da infância" (RAMIL, 2008, p. 170). "À moda do amor" (RAMIL, 2008, p. 170 e 180), como um movimento próprio do desejo, desloca-se o sentido de significante em significante, formando uma cadeia associativa - o sino, a Madrinha, o vento, o vazio, a mãe, a chuva, a camisa molhada - que leva Selbor a perceber melhor a fome que lhe afligia ao estar longe de Satolep: "[...] eu, a casa e a inundação éramos uma coisa só" (RAMIL, 2008, p. 180).

Selbor se diz um espectador, sua relação com o mundo se dá por trás das lentes: "O que resto sou apenas um olhar quieto posto nesta água toda parada em mim mesmo desde sempre" (RAMIL, 2008, p. 185). Tomemos em vista a fala de Selbor: "o que resto" nos cria um estranhamento que, possivelmente, seja um eco da expressão "o que resta é...", que se remete à não-pessoa. A fala de Selbor é subjetiva, "o que [eu] resto", diferente também da expressão "o que me resta". Pensando com Benveniste (2006, p. 230), por ser subjetiva, há uma dimensão performativa na fala, a linguagem é ação. 0 impasse de Selbor outra vez se salienta, dificultando um desenlace. Ao que João Simões, seu ente, lhe responde: "vê-se nitidamente que a casa paterna é o objeto do teu olhar, e que ela olha de volta para ti" (RAMIL, 2008, p. 191). Essa atitude e perspectiva determinam a relação de Selbor com o mundo: "estou num entretanto" (RAMIL, 2008, p. 195).

Como vimos na subseção a respeito da ilusão do espaço, nesse "entretanto", no qual Selbor se situa, encontra-se o impasse que turva as relações entre mundo interior e exterior. A casa, descrita como uma "estufa de abstrações que o pai e a mãe mantinham" (RAMIL, 2008, p. 15) é posta em oposição ao mundo externo, digno de temor: "quando via Satolep passar trazendo os passantes e por eles sendo levada", "a visão de mundo hostil adquirida na estufa familiar" e "trocou-a pela da realidade objetiva do mundo lá fora” (RAMIL, 2008, p. 108, 178 e 191). Dessa relação inóspita, emerge a melancolia de Selbor: "Como não admitir que era meu o timbre daquele vazio?” (RAMIL, 2008, p. 181).

Pela rememoração, "como restauração e reprodução, (...) e por isso mesmo, como incompleto e inacabado" (BENJAMIN, 1984, p. 68), pelos saltos originários que lhe fazem revirar seus escombros, Selbor ressignifica eventos nebulosos de sua infância, dando novos matizes às zonas cinzas que lhe assolavam. Após a estadia na casa da várzea, Selbor retorna a Satolep e passa a fotografar as suas agruras. Seu olhar como telescópio para as virtudes da terra torna-se mais crítico. Junto à calamidade trazida pelo temporal, com casas destruídas e pessoas desabrigadas, passa a ser utilizado, em referência à cidade, um vocabulário de decomposição: "quando o vento não trazia a podridão das charqueadas e dos curtumes" (RAMIL, 2008, p. 203).

A recorrência a imagens de decomposição traz consigo, ao menos, dois valores: por um lado, mostra um olhar menos condescendente do personagem para com os problemas sociais, que encontra expressão em sua flânerie e em seu projeto artístico; por outro lado, torna cada vez mais perceptível o questionável estado mental de Selbor. Para nós leitores, já não nos fica mais claro se nosso herói errante pertence a um universo mágico ou se tresloucou-se de vez. 
Em uma dessas cenas mágicas, durante a conversa de Selbor com os seres da fumaça, João Simões lhes diz: "deves te referir ao lugar em que estou não como 'aí' mas como 'aqui', porque nosso universo parece ser o mesmo, amigo Selbor" (RAMIL, 2008, p. 183). Selbor está, assim, incorporado aos entes artísticos nesse tempoespaço que já não se sabe mais onde fica.

Ao voltar à cidade, as pessoas o observam com espanto: "devo ter me expressado em voz alta, pois ao endireitar-me no banco, num esforço para não dormir, reparei que os outros passageiros me olhavam assustados" (RAMIL, 2008, p. 203). Como já dito, enquanto artista, o problema de Selbor é a luz. No entanto, ela adquire aqui outro valor:

Foi a luz que mudou. Agora é ela que não me dá descanso. (...) Sofri uma inundação de imagens. Vou precisar de muito tempo para te falar sobre elas. (...) Tudo era manifestação da luz. Nesse contexto, era natural que eu fosse ambíguo (RAMIL, 2008, p. 213-4).

Recuperando as palavras de Rouanet (1992, p. 71) a respeito do flâneur, "tudo está mergulhado no sonho, e como tal tudo é ambivalente". Luz e ambivalência. 0 excesso de luz na cidade começa a perturbar Selbor, que a olhos alheios parece vagar em uma nuvem: "Eu lhe parecia definitivamente louco ou mentiroso" (RAMIL, 2008, p. 272). Seu ocaso parece ser também o da cidade:

Se havia alguma mensagem em suas cores e sua dissolução, era a de que a ruína de Satolep anunciada pelo Rapaz em seu primeiro texto não seria desprovida de beleza [...] que os telhados desabados contariam histórias interiores $\mathrm{e}$ as madeiras carcomidas descreveriam este nosso tempo com o refinamento e a credibilidade de antigas escrituras (RAMIL, 2008, p. 275).

Selbor já não mais distingue os caminhos de sonho dos caminhos de pedra, a ficção da realidade. Ele flana por toda a cidade, evitando apenas a casa paterna: "Quando as grandes umidades começaram a chegar para apodrecer as folhas caídas, eu me senti a vagar pela superfície ainda úmida de uma fotografia recém-ampliada" (RAMIL, 2008, p. 275). Selbor já não mais fotografa, apenas deambula e, aos poucos, passa a dormir nas ruas, de onde, ao fim, é recolhido.

Apenas no final da história, o leitor pode ter mais clareza sobre a instância enunciativa. $O$ ato narrativo, a voz que enuncia, situa-se em uma posição posterior em relação à história narrada. Em função dessa ulterioridade, o tempo verbal utilizado predominantemente é o do pretérito perfeito do indicativo, assinalando ações passadas através do olhar do personagem: "Decidido a aceitar o presente da cidade, tratei de me mudar naquela tarde mesmo" (RAMIL, 2008, p. 74). 
No entanto, ao longo de toda narrativa, quando ocorrem intromissões do narrador, há o uso do presente, remetendo ao presente de fala, à cena final na instituição de saúde, de onde todo relato se organiza. Esse é o momento no qual o locutor situa como presente tudo o que está implicado, tendo como seu centro gerador e axial a coincidência entre acontecimento e instância do discurso que o menciona, segundo Benveniste (2006, pp. 74-75). É a partir do presente que a nãocontemporaneidade de acontecimentos e discurso se manifesta e que, por conseguinte, os tempos não-presentes são instaurados.

Quanto mais a narrativa se aproxima desse presente de fala, mais se impõe o narrador em seus comentários intrusos, evidenciando o lugar de onde enuncia: "Senhores, foi esse o caminho que tomei" (RAMIL, 2008, p. 273). Nas páginas finais, o pretérito imperfeito passa a ocorrer com maior frequência, trazendo o efeito de um passado de ação mais duradora e menos determinado, aproximando-se do presente: "Eu tinha a alma forte e o coração sereno [...] As coisas estavam quietas [...] Não significa que eu caminhasse sem parar" (RAMIL, 2008, p. 276). Até ser substituído de vez pelo presente, onde fundem-se o eu narrado e o eu narrante, dirigindo-se a um tu expresso: "Quero dizer com isso que os senhores são o tema da penúltima página da pasta. Permitam-me fotografá-los. Assim. Não se mexam. Obrigado" (RAMIL, 2008, p. 277).

A história narrada aproxima-se, finalmente, da narração. Pensando com Benveniste (2006), esse é o ponto que a temporalidade retrospectiva, construída a partir do presente, reencontra o presente da enunciação. Esse tu expresso, cristalizado ao longo da obra pelo vocativo "Senhores", o qual o leitor ouvia e ao qual respondia por sentir-se convocado ${ }^{8}$, ressignifica-se ao fim da narrativa. Do ponto de vista do leitor, somente nesse instante é dado a conhecer o narratário, a quem o narrador se dirigiu durante toda obra. Fazendo uso do desdobramento possível entre narratário e leitor, Satolep nos cria outra armadilha.

\section{5. $O$ QUE O TEMPO CONSTITUI NA OBRA?}

Satolep apresenta-se, assim, para usar uma expressão de Dessons (2006, p. 377), como uma aventura da linguagem, ou, para pensar com Agamben (2008, p. 12), um experimentum linguae, na qual reflexões sobre a efemeridade humana, a experiência de linguagem e a criação artística entrelaçam-se. Independentemente do fecho que atribuamos à obra - pelo viés da loucura do personagem, pela espiritualidade ou, simplesmente, pela consideração de um autor que brinque com nossos limites de leitores, colocando-nos em um labirinto - o que nos interessa é observar como a cidade se enuncia em Selbor.

A destruição do narrador - devorado pelo tempo, pelo ruir da memória - é a própria destruição de Satolep, de sua Satolep - como canta o Compositor: "A assimetria é o infinito dentro das coisas. 0 inesperado é a regra. Quando voltares, as coisas terão deixado de ser para continuarem a ser as coisas. Satolep nunca mais será a mesma" (RAMIL, 2008, p. 195). À neuf, para retomar um termo benvenistiano,

\footnotetext{
${ }^{8}$ Do latim convocare, "chamar junto". Ressalta-se, aqui, a palavra vox, "voz".
} 
cada vez nova e irrepetível: "Eram um alerta de que a planície em que Satolep fora construída poderia ser ocupada mil vezes que mil vezes renasceria, mas que Satolep existiria apenas uma vez" (RAMIL, 2008, p. 113).

Dessons argumenta que, nos escritos de Benveniste, o prefixo re-possui um peso teórico, sendo portador do valor de iteração e de invenção, assim como os pronomes je e tu (DESSONS, 2006, p. 13). Tal ideia parte do "pensamento da historicidade da linguagem que especifica cada presente de fala"9 (DESSONS, 2006, p. 14). Segundo Dessons, por essa razão, a noção de reinvenção possui uma função crítica na obra de Benveniste, enfatizada pelo prefixo re-:

Fazendo da invenção a própria origem do discurso, o prefixo reconfere à noção de reinvenção uma função crítica. Através do exercício da linguagem, o mundo não é um retorno eterno, mas uma criação constante. Nesse sentido, o prefixo funciona como um marcador de historicidade ${ }^{10}$ (DESSONS, 2006, p. 14).

A inevitabilidade das mudanças é enfatizada por esse caráter assimétrico da experiência humana, concretizando-se no mosaico, como pensou Benjamin (1984, p. 51), na justaposição de fragmentos de imagens: "Se fazer mosaicos me ensinou a ver as imagens antes de elas tomarem forma, ensinou-me também que, mesmo seguindo um plano original, elas invariavelmente mudam durante sua lenta execução" (RAMIL, 2008, p. 76). A arte e a vida são correlacionadas pelo seu caráter singular, pelo que escapa, não se deixa enquadrar: "se a vida é assimétrica, simetria é onde a assimetria se esconde e se afirma" (RAMIL, 2008, p. 120). A reflexão artística é realçada, ainda, pela figura de Lobo da Costa, poeta maldito que espelha o destino errante de Selbor: "Sou um lobo assimétrico" (RAMIL, 2008, p. 271).

Benjamin diz que "as ideias se relacionam com as coisas como as constelações com as estrelas” (1984, p. 56). Isso implica em considerar a construção de uma imagem na relação entre o todo e as partes, constelação e estrelas, uma vez que uma não pode explicar a outra por si só. Assim como a alegoria de Benjamin sobre as constelações, a exposição "Nascer leva tempo", o grande círculo de 28 fotos que oferece um mosaico de olhares sobre a cidade, impõe-se como uma tentativa de salvação dessa tragédia: "considerando minha expectativa de que o 'grande círculo' reservava para o final alguma revelação" (RAMIL, 2008, p. 272).

Compreender a cidade e a si através da arte, pela lente (telescópio, câmera olhar), pela construção de uma imagem, surge como a possibilidade de individuação (DESSONS, 2006, p. 110), de singularização pelo exercício da linguagem em um aqui e agora. Essa individuação, no entanto, dá-se no diálogo de um aqui e outrora reconstrutivo de diferentes discursos, nos saltos temporais originários que os

\footnotetext{
9 Tradução minha. No original: "pensée de l’historicité du langage qui spécifie chaque présent de parole". ${ }^{10}$ Tradução minha. No original: “ En faisant de l'invention l'origine même du discours, le préfixe re-confère à la notion de réinvention une fonction critique. Par l'exercice du langage, le monde n'est pas un éternel retour, mais une constante création. En ce sens, le préfixe re-fonctionne comme un marqueur d'historicité".
} 
apresentam como fragmentos da verdade - como mônadas que contêm em si potencialmente a imagem do mundo (BENJAMIN, 1984, p. 70).

Para tanto, é preciso que se "aprenda a ver" (RAMIL, 2008, p. 105), como sentencia o irmão mais velho, sendo ecoado pelo Rapaz. Seguindo os passos do irmão, é pelo deslocamento, o rompimento com a linearidade, que a visão se aprimora. Aguçar o olhar e focalizar não o óbvio, mas sim "fotografar o que deixava de fora das fotos" (RAMIL, 2008, p. 166), nessa busca por "escovar a história a contrapelo", como nos alertava Benjamin (1987, p. 225), para enxergar ali o que está encoberto em sombras e pulsa em potência. Assim como o Anjo da História benjaminiano (BENJAMIN, 1987, p. 226), Satolep parte do trabalho de confronto com os escombros, enfrentando o progresso que lhe empurra para longe da experiência: "Seguem minhas visões de Satolep em ruínas. Hoje foi nossa casa que eu vi: telhado e muro desabados; a face norte destruída, sala, copa e cozinha entregues à ventania" (RAMIL, 2008, p. 7).

Ainda que Selbor não escape ao destino que se desenha ao longo da obra, seu intuito se realiza. O retratista logra dar cabo à concepção de seu "Grande Círculo", que deverá ser apresentado com o nome de "Nascer leva tempo". Esse trabalho, resultado de uma experiência no limiar da familiaridade e da estranheza, toma corpo na técnica da montagem, no sentido benjaminiano, tendo o mosaico dos diferentes olhares sobre Satolep como meta de sua apresentação. Satolep poderia ser livremente lido somente por suas páginas pretas - suas fotos e seus fragmentos textuais - apresentando-se como um caleidoscópio no qual o leitor, a cada movimento, construiria uma nova combinação, um novo délibáb.

$\mathrm{Na}$ globalidade da narrativa, os instantes fotográficos e textuais da "pasta preta" funcionam, em seu exercício, como um contraponto ao "telescópio voltado às virtudes da terra" (RAMIL, 2008, p. 9 e 130-131). As identidades refundem-se, assim, constantemente: "Um mosaico se faz enquanto é feito" (RAMIL, 2008, p. 77), adverte o Cubano, realçando o devir da experiência de linguagem: "dê-se tempo. Faça-se e deixe-se fazer. [...] Nascer leva tempo" (RAMIL, 2008, p. 77). No e pelo exercício da linguagem, Selbor escava a si mesmo, suas camadas e desdobramentos, numa busca de identidade artística e pessoal em constante fluidez, nessa história inventada na qual quem fala de si se confronta, se instaura e se historiza, como nos mostrou Benveniste (2005, p. 84), ou como carinhosamente observou João Simões:

As almas dão longas voltas. Por isso são naturais às crianças e caras aos artistas: ambos, cada qual à sua maneira, movem-se ininterruptamente. [...] 0 princípio é a alma, o emergir de tudo. E no fim ela também está. Mas se pudesses fotografá-la verias que é no movimento entre essas duas posições que fica a sua casa (RAMIL, 2008, p. 194).

Em seu retorno à casa familiar para tomar seu retrato final, Selbor depara-se com uma criança cujo relato, na derradeira página preta, descreve a chegada do retratista e evidencia estar em vias de partir para longe de Satolep. Em Satolep, o fim da narrativa é, também, o seu início, mas não é retorno ao mesmo. 0 presente olha ao passado que lhe devolve o olhar em interrogação. Os ciclos se completam 
apenas ali naquele fugidio instante que se tocam e seguem seu curso, ali onde se encontra o homem.

\section{CONSIDERAÇÕES}

Segundo Agamben (2008), a discussão de linguagem como constituidora muda a perspectiva das ciências humanas. Ao voltar-se ao singular, essa concepção de linguagem rompe com a tradição da ciência positivista, totalizadora, da qual Benjamin se ocupou explicitamente em sua crítica ao programa filosófico da modernidade. Partimos, aqui, da singular construção dos objetos, não de uma categorização prévia. Visto a partir dessa concepção de linguagem, o tempo só pode ser pensado a partir do presente, sendo indissociável da voz que o enuncia. Benveniste observa em detalhe como se dá o processo de apropriação da língua e a construção temporal a partir de um eixo linguístico que toma o "eu" como referência, em um olhar sincrônico. O tempo originário, nascido no ato de apropriação da língua, é a voz particular. Por essa via, tudo é semantizado pela linguagem. Benjamin, por sua vez, observa - em uma espécie de diacronia, mas aos saltos descontínuos como se dá o processo de reconstrução do passado e o porquê do não fechamento de seus sentidos no presente. Seu ponto de partida é sincrônico, mas de uma sincronia que se deixa interrogar pelas imagens dialéticas, trabalhando com as simultaneidades.

Ao passo que Benveniste afirma que só temos verdadeiramente acesso ao presente, e que a instância de fala constrói o passado retrospectivamente, Benjamin frisa que esse presente é repleto de história, dialogando com outros discursos (vozes) que, tendo sua enunciação evanescida, são revisitados, ressignificados. Segundo os autores, temos acesso somente ao presente, mas há a memória, acessada (reconstruída) pelo presente, pela voz. 0 passado que emerge no presente, evocado pela memória, é sempre singular, posto que atualizado pela língua em uma nova instância enunciativa, em um novo tempo e espaço. A enunciação, o tempo da coincidência do acontecimento com a instância de fala, é o tempo da voz, onde há sujeito e, portanto, história. Nesse sentido, Benjamin e Benveniste parecem complementar-se.

A leitura de Satolep, a que nos propusemos, buscou tomar a obra em sua singularidade, por uma concepção de tempo que, como realçamos, nasce com o mundo toda vez que falamos: "cada vez que a palavra expõe o acontecimento, cada vez o mundo recomeça" (BENVENISTE, 2005, p. 31). O leitor termina por não saber ao certo o segredo da pasta preta - o que contribui para a atmosfera misteriosa de Satolep. Não há explicação direta. Quando o homem encontra consigo em infância, resta ao leitor preencher esse movimento, onde o mundo narrativo recomeça. Mais importante que os enquadramentos são, assim, as relações que se podem estabelecer na obra, os valores que dela emergem. 0 tempo é construído a cada enunciação, sendo, por essa razão, o espaço fundamental da emergência, da singularidade. Satolep apresenta-se como apenas uma forma de conceber o tempo, singular. Satolep mostra especulações, espelhamentos que não são simplesmente da ordem do um para um, do verso e reverso - mas sim, e é importante que se diga, 
são Fata Morgana, délibáb, ilusões, deformações. A rememoração (Eingedenken) não é simples lembrança que traz o ausente, uma vez que ela o explora tanto quanto se deixa explorar por ele - como o homem que olha para si criança que lhe devolve o olhar. Por fim, a própria forma da narrativa, sua apresentação cíclica e suas linhas diegéticas cruzadas, parece, de certo modo, espelhar os temas de que ele trata: a construção urbana, identitária, artística e do tempo como repletos de anacronias que emergem do devir.

\section{Referências}

AGAMBEN, Giorgio. Infância e história: destruição da experiência e origem da história. Tradução: Henrique Burigo. Belo Horizonte: Editora da UFMG, 2008.

ANJOS, Aroldo Garcia dos. Lavrar a névoa: o tempo em Satolep, de Vitor Ramil. Dissertação de mestrado. Orientação: Daiane Neumann. Programa de PósGraduação em Letras. UFPel, 2020.

BENJAMIN, Walter. Origem do drama barroco alemão. Tradução, apresentação e notas: Sérgio Paulo Rouanet. São Paulo: Brasiliense, 1984.

BENJAMIN, Walter. Magia e técnica, arte e política: ensaios sobre literatura e história da cultura. Obras Escolhidas, Vol. I. Tradução: Sergio Paulo Rouanet. São Paulo: Brasiliense, 1987.

BENJAMIN, Walter. Charles Baudelaire, um lírico no auge no capitalismo. Tradução: José Martins Barbosa, Hemerson Alves Baptista. São Paulo: Brasiliense, 1989.

BENJAMIN, Walter. Passagens. Tradução: Irene Aron e Cleonice Paes Barreto Mourão. Belo Horizonte: Editora UFMG, 2009.

BENVENISTE, Émile. Problemas de Linguística Geral I. Tradução: Maria da Glória Novak e Maria Luisa Neri, com revisão de Isaac Nicolau Salum. Campinas: Pontes Editores, 2005.

BENVENISTE, Émile. Problemas de Linguística Geral II. Tradução: Eduardo Guimarães, Marco Antônio Escobar, Rosa Attié Figueira, Vandersi Sant'Ana Castro, João Wanderlei Geraldi, Ingedore G. Villaça Koch, com revisão técnica de Eduardo Guimarães. Campinas: Pontes Editores, 2006.

DESSONS, Gérard. Émile Benveniste: l'invention du discours. Paris: In Press Eds, 2006.

DESSONS, Gérard; NEUMANN, Daiane; OLIVEIRA, Giovane F. Émile Benveniste e a arte do pensar. In: ReVEL, vol. 18, n. 34, 2020. Tradução: Daiane Neumann e Giovane Fernandes Oliveira. 
MESCHONNIC, Henri. Le Signe et le poème. Paris, Gallimard: 1975.

NEUMANN, Daiane. A construção da significância na e pela voz. In: Revista

Desenredo, v. 13. Passo Fundo: Editora da UPF, p. 658-676, 2017.

NEUMANN, Daiane; ANJOS, Aroldo. A atualização da experiência humana: o poema em questão In: Revista Desenredo, v. 16, n. 1. Passo Fundo: Editora da UPF, p. 101-113, 2020.

PACHALSKI, Lissa; ANJOS, Aroldo. Considerações acerca do conceito de atualização sob os pontos de vista formalista e enunciativo. In: Revista Investigações, Recife, v. 32, n. 2, p. 189-206, 2019.

RAMIL, Vitor. Satolep. São Paulo: Cosac Naify, 2008.

ROUANET, Sérgio Paulo. É a cidade que habita os homens ou são eles que moram nela? História material em Walter Benjamin - Trabalho das Passagens. In: Revista USP, p. 45-72, 1992.

TRABANT, Jürgen. Über die Farbe der Wörter und Sprachen. In: ESSLINGER, E.; VOLKENING, H.; ZUMBUSCH, C. Die Farben der Prosa. Freiburg: Rombach Verlag, p. 29-43, 2016.

TRABANT, Jürgen. Sobre a cor das palavras e das línguas. In: Revista Linguagem \& Ensino, v. 23, n. 3, p. 881-893. Pelotas: 2020. Tradução: Aroldo Garcia dos Anjos.

\section{Para citar este artigo}

ANJOS, A. G. dos. A insistência do significante em Satolep, de Vitor Ramil. Macabéa - Revista Eletrônica do Netlli, Crato, v. 10, n. 3, 2021, p. 119-133.

\section{O Autor}

AROLDO GARCIA DOS ANJOS é doutorando e mestre em Letras pela Universidade Federal de Pelotas (UFPel). Graduado em Letras Alemão/Português pela Universidade do Vale do Rio dos Sinos (UNISINOS). Professor de alemão e tradutor. Interessa-se por discussões de língua, literatura e tradução. 